\title{
Squeezing Out the Mountain Gorilla
}

\author{
A. F. G. Groom
}

The author's 1972 census, following one the previous year, of the mountain gorillas in the Virunga Volcanoes, which straddle the Zaire-Rwanda-Uganda borders, shows a small but still declining population. All the signs, including the behaviour of the gorillas, one of which fled screaming at the sight of one of the observers, suggests that the decline is due largely to human interference. As the entire area has national park or game reserve status the urgent need is to enforce the law.

In our report on our 1971 gorilla census in the Virunga Volcanoes we observed that if incursions into the sanctuary continued at the then current rate, the six mountains would become isolated by the human pressures on their lower slopes, and the mountain gorilla would not survive on the peaks alone. In the light of our work in 1972 the prediction seems prophetic. Of the six mountains within the park, we found no gorillas on one, and another with only a tiny population showing signs of harassment which can only lead to their disappearance. Indeed, 1972's findings emphasise the very precarious position of the species in this area, which is part of the tiny fraction of the gorilla's range designated a national park.

The project was initiated by Dian Fossey, herself engaged on behavioural studies of the mountain gorilla $G$. $g$. beringei, to establish the exact status of the species within the Virunga Volcanoes. (See Oryx XI, 5). The six volcanoes, shown on the map, stretch across Africa's Central Rift Valley between Lakes Kivu and Idi Amin Dada (Edward). Two active volcanoes continue the chain to the west, but have no gorillas. The area with which the census is currently concerned is divided between the Zairois Parc des Virungas, the Rwandan Parc des Volcans and the Ugandan Gorilla Game Reserve, and thus suffers from divided responsibility for administration, including wildlife protection. The area searched now includes almost all the Parc des Volcans, the Ugandan Reserve and most of that portion of the Zaire mountains which adjoin either Uganda or Rwanda.

The 1971 census, sponsored by the National Geographic Society and the FPS, was an exploratory one, designed to test the feasibility and usefulness of the method, as well as to begin the gorilla count. The 1972 census was enlarged and the three-month study aimed to include three aspects:

1. to establish the exact status of the population in the park's eastern sector, and so provide reliable data to counter proposals, currently being vigorously advanced by certain European advisers to the Agricultural Ministry, for the establishment of a cattle breeding project in Rwanda's Parc des Volcans;

2. to collect information on the current, illegal use of the park by the local population and its effect on the gorillas. The corollary of that is, 


\section{1:50,000}

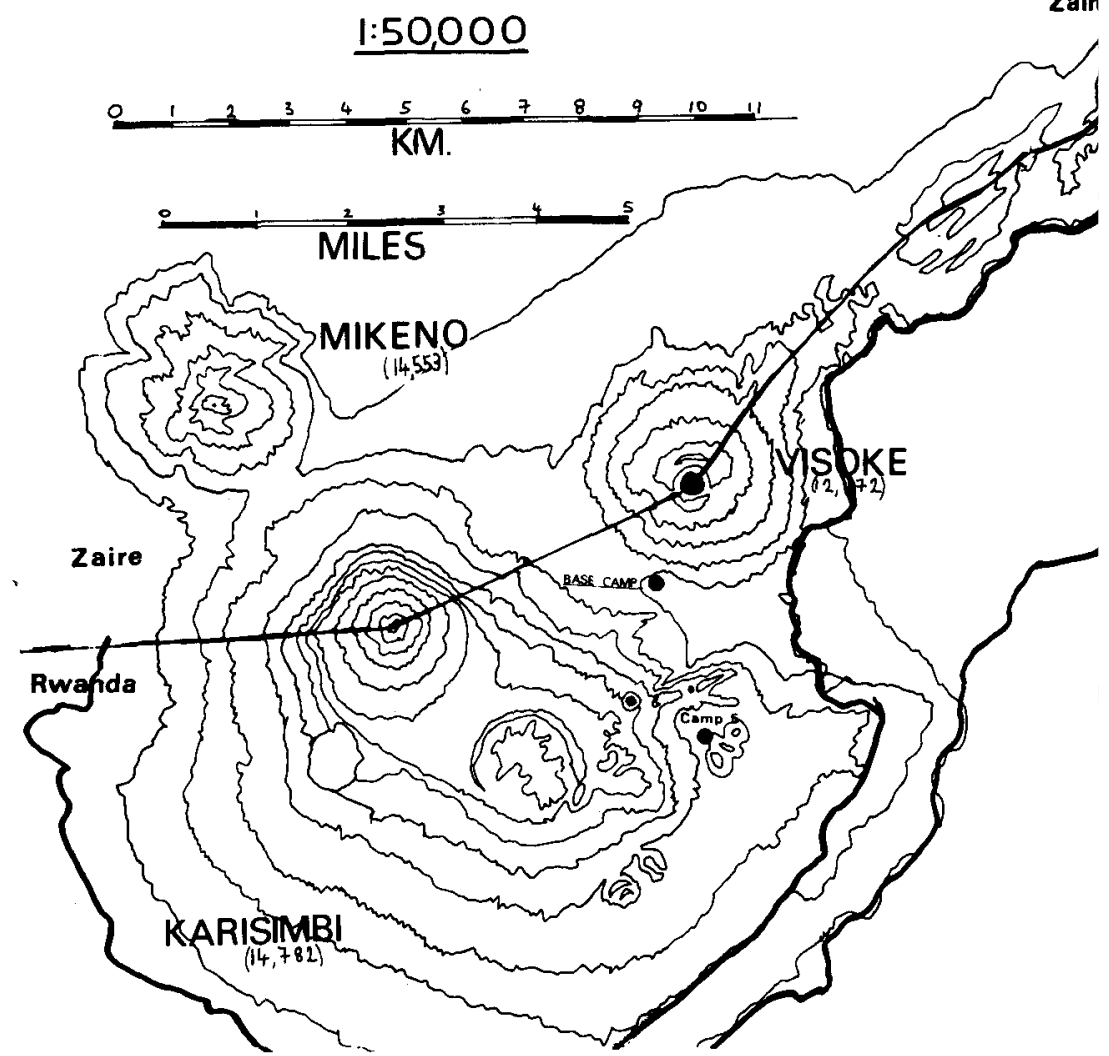

of course, the effectiveness of the park administration and the investigation of possible ways to assist it;

3. to complete a vegetation map of the Parc des Volcans.

The four of us-W. A. Laurie, I. W. Laurie, C. C. West and A. F. G. Groom - arrived in Rwanda on July 14th, and moved to our first search area four days later. Our census target was to complete the search of the easternmost mountains, Gahinga and Muhavura, and to overlap with the 1971 census by completing the search of the north-east of Sabinio and repeating the 1971 work on Sabinio to see if there had been any shift or radical change in the population. The intervening saddles were, of course, also searched.

'Noseprints' of ten gorillas in a group of twelve on Karisimbi

1.

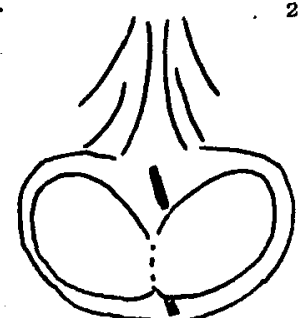

S ILVERAA CKED
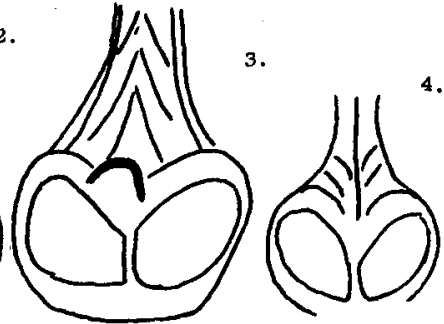

4.

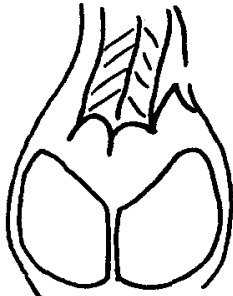

sity Press

OLD FEMALE

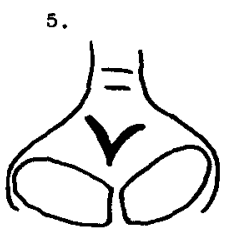

INFANT 


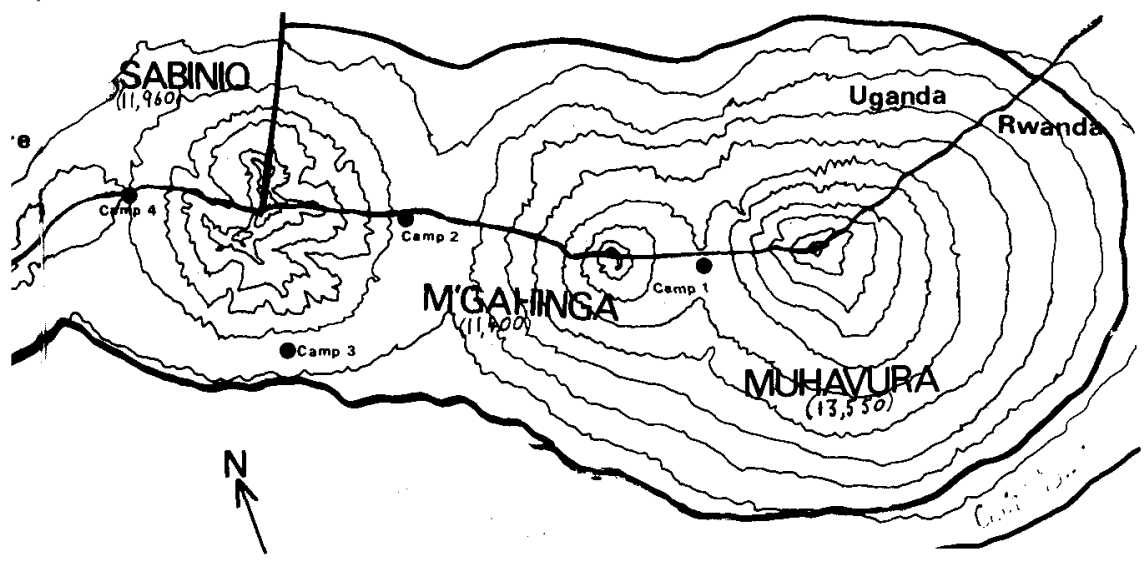

\section{Method and Results}

Our method was to make a systematic sector search of the area, noting all signs, following fresh trails, and, where possible, making contact with the animals. With luck and a certain amount of patience, it was possible to identify individual gorillas by taking a 'nose-print' - a simple line drawing of the characteristic nostril shape and the distribution of wrinkles on the bridge of the nose: the drawings below are a sample of ten noseprints from a group of twelve animals on the southern shoulder of Karisimbi. We also took notes on the vegetation and on any signs of human use of the park. We always tried to contact the gorillas, but our census results would have been both misleading and probably inaccurate if they had been based on inference from fleeting contacts, and we confirmed each group count by a series of consistent night-nest counts. The census results are summarised, by mountain, in Table 1 .

On Muhavura, the easternmost volcano, we found only thirteen animals, although the mountain's circumference at its base is many times greater than that of Visoke, where the known population may be as large as ninety-six. We also found a silverback which had been dead for some two or three weeks, but no indication of the cause of death. Gahinga, on which gorillas have frequently been reported, brought even greater disappointment, with no fresh signs at all. Even very old sign, which can give evidence of past gorilla occupation for up to a year or more, was very sparse. On Sabinio however, the situation was much more encouraging; a complete search of the mountain established the total population at 32 .

Only two of us (Groom and West) remained for the last week's work, which included the south-eastern slopes of Mount Karisimbi, and provided many interesting and important comparisons, with regard both to terrain and vegetation and also the gorillas' behaviour and their reaction to human observers. Eighteen gorillas in three groups were counted in this final week.
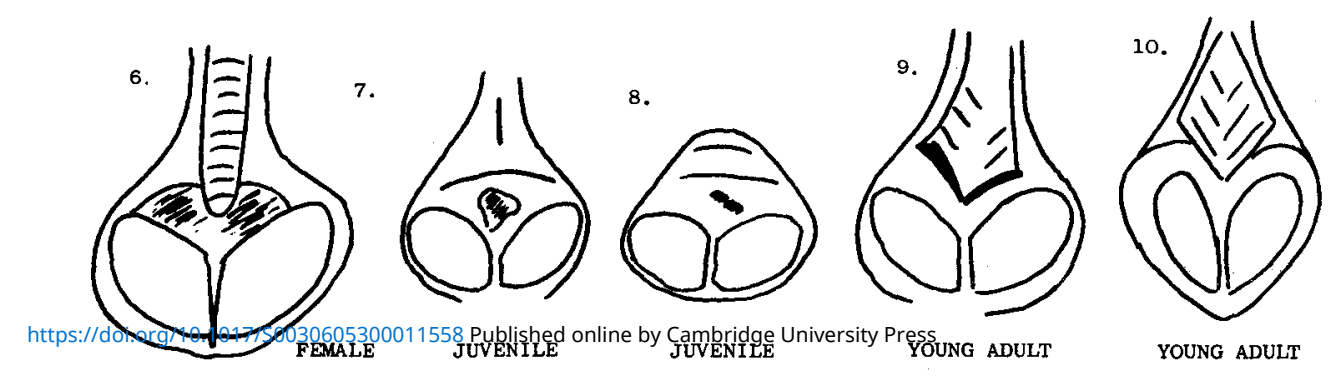

YOUNG ADULT 


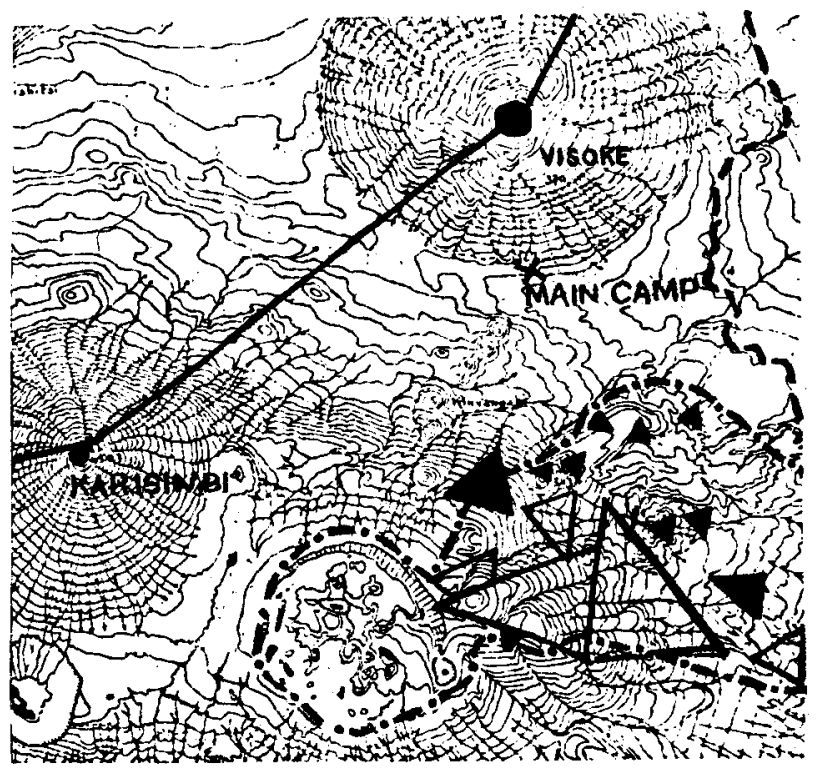

INTERNAT IONAL BOUNDARY

PARK, RESERVE BOUNDARY

AREA COVERED BY CENSUS

//. Lava

$X$ CAMP SITES

$\triangle$ OLD* AND NEW AREAS OF OONCENTRATED USE

$\triangle$ OLD SIGN ONLY

*POINTS FORMING TRIANGLES ON SABINYO TWICE AS DENSE AS THOSE FOR MUHAVURA

It was impossible in so short a time to attempt a behaviour study, but the sharp contrast in the gorillas' reaction to humans in the east of the park compared with those on Karisimbi suggested causes that were directly relevant to our census.

A comparison of the number of noseprints taken was significant: of forty-five animals counted in the east of the park, only five noseprints were obtained from twenty-five brief contacts; of the eighteen animals found to the south of Karisimbi, fifteen noseprints

Table 1: Results of Census Count

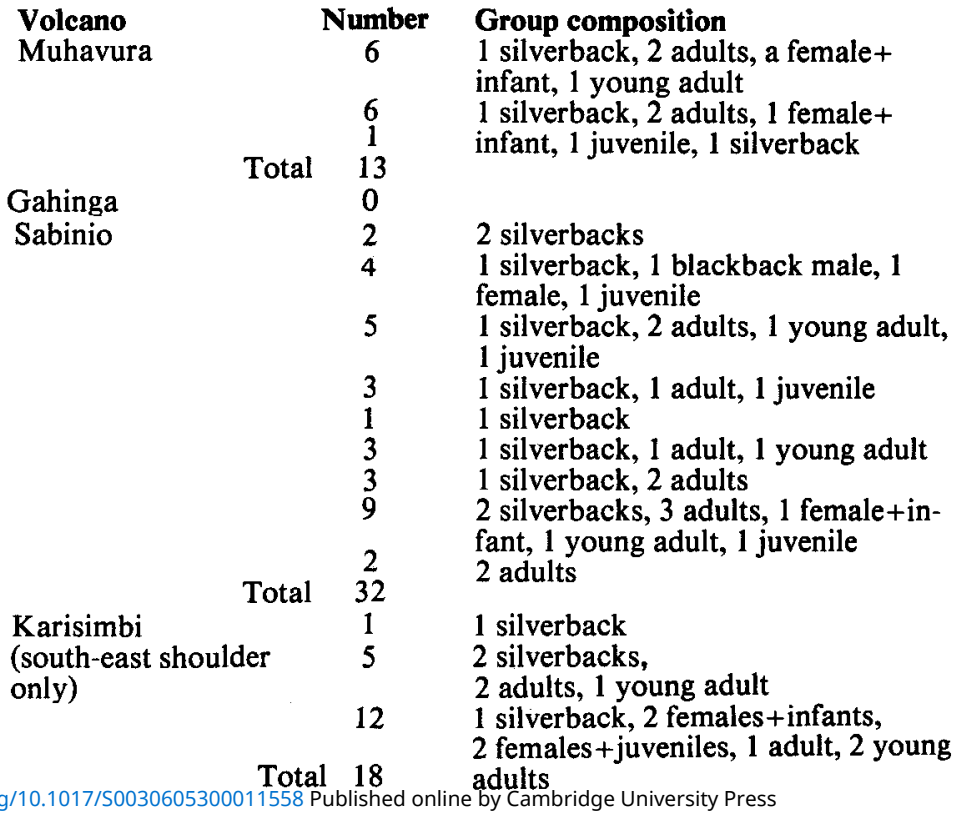




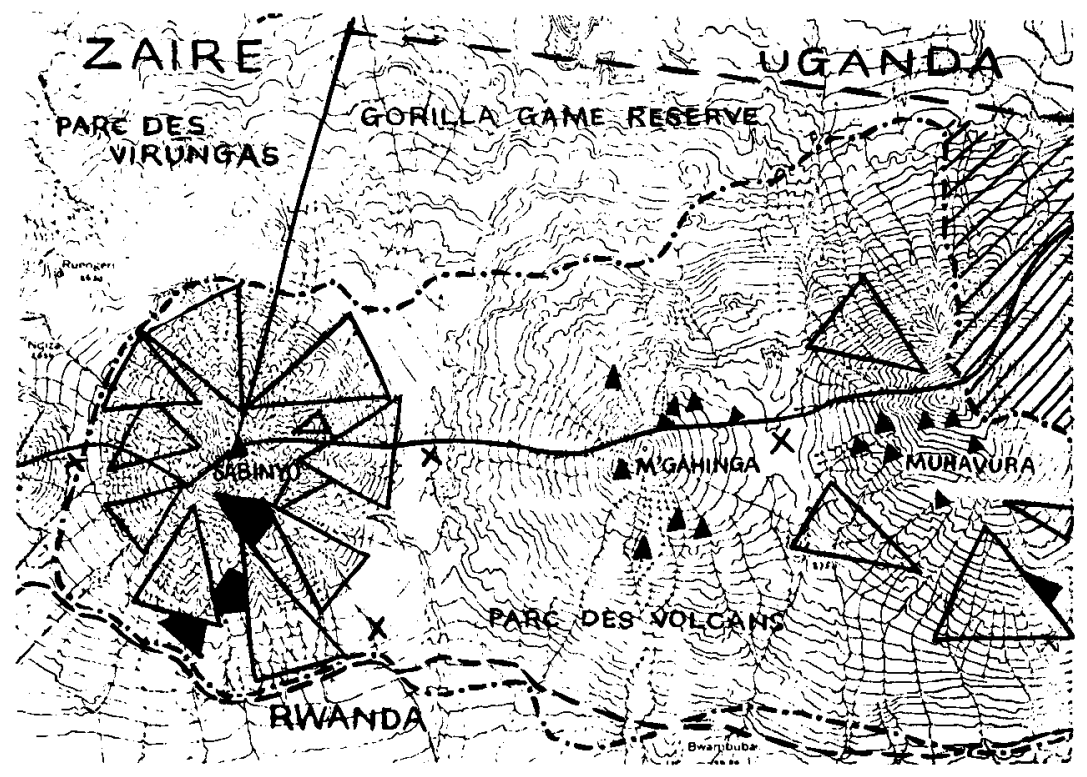

were obtained from only five prolonged contacts with almost unconcerned animals.

On Karisimbi we spent an average of only one hour a day tracking, due to the regularity of the groups' ranging behaviour. Other workers have reported a similar experience. Schaller (1963) noted that in the Mikeno-Karisimbi saddle area, he "could without difficulty pick up a trail four to five days old and trace it to the gorillas within a few hours'. On Mt Muhavura, however, an average days' tracking, that is, following a group from one afternoon's contact point to that of the next morning, could take up to four hours due to the animals' nervousness.

All the gorillas in the eastern end of the Park showed characteristic fear reactions. The most marked was when the silverback in a group of four on Sabino bluff-charged the observer from 40 yards and then fled, screaming at intervals of 10 seconds, and continued to scream for 20 minutes; the frequency slowed until he was heard only about twice a minute, during which time he travelled about half a mile-his screams still clearly audible. Even though such extreme fear was exceptional, the most usual reaction was silent flight as soon as the observer's presence was noted; and often that was as soon as or even before the observer was aware of the gorillas!

On Karisimbi, however, the observer's presence elicited no more than an alarm bark and a retreat of a few yards. Appeasement gestures (scratching, turning away, hooting softly or huddling low) invariably overcame their initial alarm, and further 'behaviour' on the part of the observer ('feeding', grooming, grunting) invariably aroused sufficient curiosity for at least some animals to come closer to have a look! Furthermore, it must be remembered that the Karisimbi animals (lone silverback, all-adult group, large group with a preponderance of females and young animals) represent the 
most diverse group compositions commonly found, so that the explanation of the widely differing behaviour in the two areas could not justifiably be ascribed to differences in group composition.

Indeed, the Karisimbi animals presented us with quite extraordinary instances of fearless behaviour. Schaller (1963) reported that 'the animals were never noted on the large meadows'. At $4.00 \mathrm{pm}$ on September $17 \mathrm{th}$ a lone silverback appeared from the forest less than 50 yards from a tent outside which Africans were working, barked twice, retreated to the edge of the forest, sat down for a moment or two, and then slowly ambled across the meadow at its widest point, turning at the far side, to tear at some vegetation, thump the ground twice and disappear into the forest-behaviour unprecedented for its confidence.

A final, but very significant comparison concerns the relative group compositions. It was pointed out that the composition of the groups on Muhavura (see Table 1) with only one infant or juvenile per group, indicated a declining population. This is certainly not the case on Karisimbi where young adults, juveniles and infants comprise half the group.

\section{Human Influence}

The differences in population density and structure and in the gorillas' behaviour in the two areas are difficult to account for. Probably, many factors, including vegetation differences, terrain, and the rest of the park fauna, play some part, but there can be no doubt that human interference has contributed very significantly to the harassment of the gorillas in the east of the park and is certainly responsible for their near-absence on Gahinga and Muhavura.

During our three months in the Virungas, we made a note of any illegal incursions we happened to see-see Table 2 . It has to be remembered that we spent only two months in the eastern end of the park, and also that we were engaged in a study which took us to areas that should have been quite remote from the local people's activities.

One factor both isolating Gahinga and interfering with the gorilla population on Muhavura is the existence of well-worn smuggler routes between Uganda and Rwanda on both the Sabinio-Gahinga and Gahinga-Muhavura saddles. Although it would seem to be in the interests of both governments to put a stop to this, apparently nothing is done. The volume of traffic is considerable; our African trackers estimated, and our own observations bore them out, that a group of between ten and twenty smugglers pass along the Sabinio-

Table 2: Illegal Use of the Parks

Camp site no.

Man days worked at site

Poacher groups seen

No. of poachers seen

Poacher groups heard

Smuggler groups

Total smugglers

Traps found

Cattle herds

Total no. cattle

Wood/grass-cutters

\begin{tabular}{|c|}
\hline $\begin{array}{r}4 \\
20\end{array}$ \\
\hline- \\
\hline 2 \\
\hline$\tau$ \\
\hline 13 \\
\hline 3 \\
\hline 26 \\
\hline 3 \\
\hline
\end{tabular}


Gahinga route every half hour of the day: and the GahingaMuhavura route is used only slightly less frequently. The groups travel noisily, in order to frighten away the larger game, and we saw signs that they occasionally camp overnight in the park.

A forest footpath would not necessarily be of consequence, but the activities of wood-cutters, grass-cutters (the grass is used for thatching) and cattle herdsmen have converted most of the SabinioGahinga path into a highway-like meadow, rarely less than thirty yards across. Gorillas tend to shun open spaces, and such a path in constant use would present a barrier to species much less shy than the gorilla. The Gahinga-Muhavura saddle presents a similar though less severe barrier to normal animal movements.

Moreover, the Uganda sector is designated only a Gorilla Reserve and we found that this status appeared to give the local population complete licence to use the areas as they wished, short of establishing shambas. We saw scores of wood and grass-cutters, and many cattle herds, and teams of poachers were heard almost daily. In Uganda, but less often in Rwanda, the poaching consisted of a line of poachers and dogs with bells round their necks driving the game towards waiting bowmen or spearmen, a form of hunting that is much more disturbing that the trap lines also often found. It was hardly remarkable that, at the time of our census, there were no more than twelve animals in the entire Ugandan sector of the gorilla sanctuary.

But it would be wrong to assume that the position is much better in other parts of the Virungas. Cattle, poachers, wood-cutters, beekeepers, smugglers, and so on, may be found throughout the mountain chain. In the dry months, the only accessible water for people living near the park boundary may be deep within the park itself. 
Since the inception of the parks, there have been continual demands for land in them-the map shows differences between the original and present boundaries of the Rwandan Park. Now there is again mounting pressure for land for the cattle-breeding project.

Schemes also exist for piping water out of the parks; a pipeline already runs from the Gahinga-Muhavura saddle towards Uganda, and Rwanda wants to establish a pipeline from the crater lake on Visoke.

\section{Discussion}

The 1972 census has established that there is an unexpectedly small and still declining population of only forty-five gorillas in the entire eastern end of the Virungas, including Sabinio, Gahinga and Muhavura. It has also established beyond reasonable doubt that two major causes of the low population are human interference and territorial restriction.

The absence of gorillas on Gahinga is probably due to a combination of unsuitable vegetation (the bamboo that covers much of the lower slopes is probably only suitable for forage in May and September when it is shooting), and human interference, plus interference from other species, notably elephant and buffalo, at unwontedly high altitudes. Elephant damage, for instance, was observed at all altitudes from 8000 to 12000 feet, but was most severe in the higher zones, especially in the Hypericum woodland, a zone most suitable for gorillas. Nine elephants were noted in or around the summit crater for several days at a time. It is most probable that human occupation of the lower areas has driven the large game species higher than they would otherwise commonly be found, and that over-usage by a concentrated number of previously well-distributed browsing species mutilates the vegetation which would otherwise be available for the gorillas.

Our conclusion must be that, if the mountain gorilla is to survive in the area, territorial encroachment must cease and human interference be reduced. In other words, the status of the Virungas as a national park or reserve must be respected. Zaire signed (but has not yet ratified) the 1968 African Convention for Conservation of Nature and Natural Resources, under which the gorilla is totally protected, and the signatories concerned have undertaken to protect its habitat. The problems of enforcing national park or reserve status are aggravated because the African officials do not have sufficient motivation to carry out their duties. Poorly paid, they are much more inclined to accept bribe money from poachers and cattlegrazers who can afford substantial sums.

Poachers rarely seem to attack gorillas directly, but the witchcraft motive is still strong. The dead silverback which we found intact on Muhavura and moved to Miss Fossey's camp at Visoke had its ears, tongue, genitals and the terminal phalanx of each little finger cut off on the journey, even though we had paid guards to prevent interference with it. Our trackers assured us that these parts of a large male gorilla were powerful witchcraft 'weapons' against an enemy. In the 1971 census we found a silverback which had 
apparently been killed expressly for such purposes.

The encroachment threat is more insidious but potentially more catastrophic. Pressure to release land for an agricultural project is difficult to resist, especially if no catastrophic harm appears to threaten the remainder. Indeed, the history of the Virunga Parks is one of continual appropriation of land. Water conservation is another strong argument against the appropriation of more land in the parks, and so too are the probable effects of the inevitable removal of the vegetation, if the land was sequestered. Moreover, the removal, for instance, of the Rwandan sector bordering on Uganda would most certainly cause the disappearance of the gorilla from the Ugandan reserve.

Finally the other wildlife in the area should be considered. It is most unlikely that the elephants, for instance, could be accommodated in a smaller area without serious overcrowding problems, and further appropriation of land would probably mean the extermination of elephant, buffalo, duiker, bushpig, bushbuck and so on, not to mention the thirteen gorillas on Muhavura. There would be some grounds for hope if the proposed agricultural project could be changed to one that would exploit the tourist potential of Africa's oldest national park, which is clearly great.

The first essential for this is vigorous enforcement of the principles and statutes of a national park, preferably with a single authority for the areas in all three countries. When the present boundaries of the Rwandan Park were established, a start was made to protect it by marking the boundary with a ditch and bank, serving both to keep cattle out and animals in. Enthusiasm quickly waned, the effort petered out, and the short stretches that were built are now broken and useless. But given determination, the parks and reserve of the Virunga Volcanoes could be worthy of the rare species they contain and a material asset to the people of the area.

\section{Acknowledgments}

We would like to offer our most grateful acknowledgments to the Fauna Preservation Society (FPS) for generous travel grants, and to the National Geographical Society (NGS) and the World Wildlife Fund (WWF) for generous grants to maintain us in the field. A. F. G. Groom was also most grateful to receive a Hamlin Bursary Award from St. Catharine's College, Cambridge.

We would also like to thank the Rwandan and Zaïrois Conservateurs of the Parc des Volcans for their kind permission for us to work in the park. Finally, we are indebted to Miss Fossey for her generosity and constant support; the census is her project in that, without her, it would not have taken place.

\section{References}

HARCOURT, H. H. \& GROOM, A. F. G., Gorilla Census, Oryx. XI, 5.

ROBYNS, W. 1948. Flore des Spermatophytes du Parc National Albert, Institut des Parcs Nationaux de Congo Belge.

SCHALLER, G. 1963. The Mountain Gorilla. Chicago.

SPINAGE, C. A. 1969. Report of the Ecologist to the Rwanda National Parks. Ministry of Overseas Development. 